\title{
Artelogie
}

Recherche sur les arts, le patrimoine et la littérature de l'Amérique latine

5 | 2013

Femmes créatrices en Amérique latine : le défi de synthétiser sans singulariser

\section{El trabajo recompensado: mujeres, artes y movimientos femeninos en la Buenos Aires de entresiglos}

Georgina Gluzman

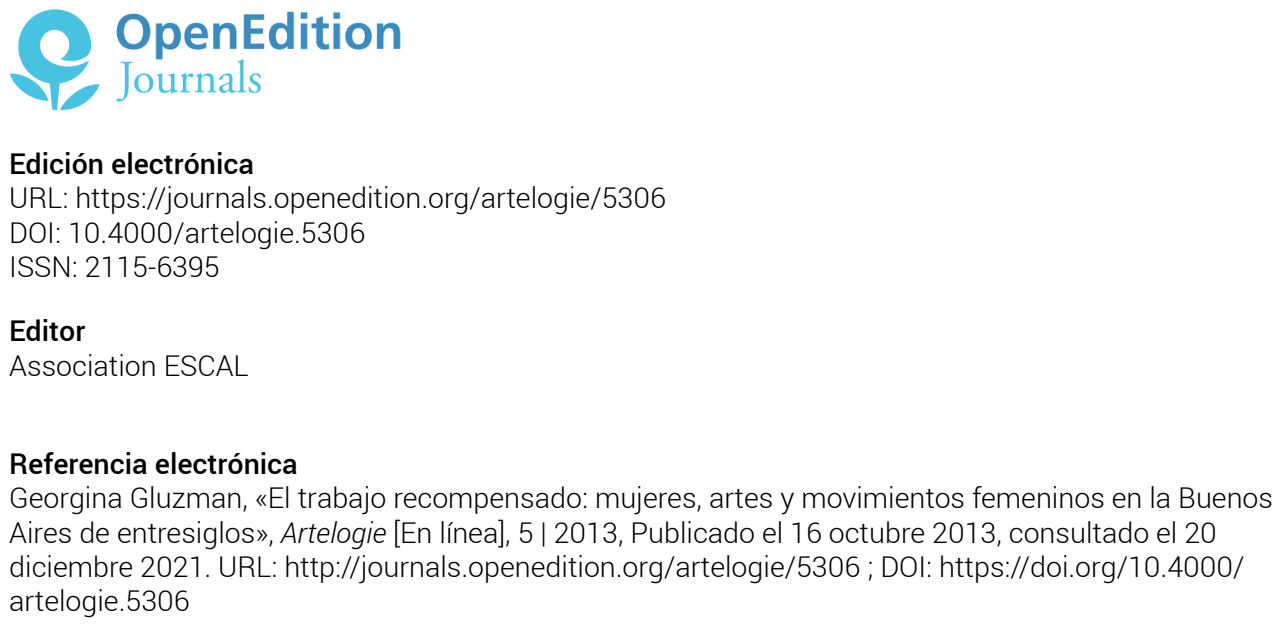

Este documento fue generado automáticamente el 20 diciembre 2021.

Association ESCAL 


\title{
El trabajo recompensado: mujeres, artes y movimientos femeninos en la Buenos Aires de entresiglos
}

\author{
Georgina Gluzman
}

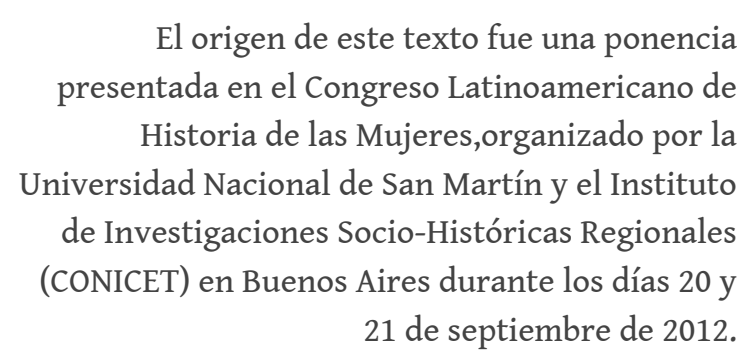

Si bien durante los últimos veinte años la historia del arte en Argentina ha atravesado un profundo proceso de cambio, el impacto de los estudios de género no ha sido tan contundente. No obstante, los escasos trabajos sobre mujeres artistas activas entre fines del siglo XIX e inicios del XX han puesto de manifiesto su relevante participación en el campo artístico local. Pero, además, se torna necesario justipreciar la participación de las mujeres en la promoción y sostenimiento de las artes (cfr. MALOSETTI COSTA, 2011).

2 Las dificultades a la hora de hallar datos referidos a las actividades artísticas femeninas han jugado un rol importante en la escasa atención concedida a este período, que vuelve imprescindible la movilización de las más diversas fuentes. De este modo, aspectos como la educación artística femenina no han sido estudiados sino hasta fechas recientes (cfr. ARIZA, 2012; GLUZMAN, 2012; SCOCCO, 2008). En este trabajo nos proponemos explorar un conjunto heterogéneo de documentos-publicaciones periódicas, actas de congresos, artículos periodísticos y memorias de asociaciones de beneficencia-, muchos de ellos aún pobremente conocidos.

El pensamiento de los tempranos movimientos de mujeres en Buenos Aires fue sumamente productivo en la exploración del valor y las posibilidades de la creación artística femenina, en sintonía con la "marcada inclinación por el fomento de la 
educación artística de la mujer, especialmente en lo relacionado a las llamadas 'artes menores" (SCOCCO, 2008: 215). En este trabajo analizaremos un conjunto amplio de asociaciones, actividades y representaciones, considerando que todas ellas responden al surgimiento de una "conciencia femenina" (KAPLAN, 1982: 545) sostenida por objetivos comunes tanto a feministas como a filántropas no alineadas con el feminismo (cfr. GUY, 2009: 8). ${ }^{1}$

Hemos considerado asociaciones femeninas de diverso signo ideológico -las decididamente feministas y las más conservadoras-, entendiendo siempre que éstas contribuyeron a un proceso de revaluación de los roles femeninos en la sociedad en momentos donde una gran cantidad de intelectuales defendían con ahínco la inferioridad femenina (BARRANCOS, 2008: 9; GUY, 2009). ${ }^{2}$ Como ha señalado Lavrin: "No hubo un feminismo sino una diversidad de respuestas de orientación femenina a los problemas experimentados por mujeres de distintos estratos sociales" (1995: 4; el destacado es nuestro).

5 El pensamiento en torno a la función e importancia de las mujeres artistas, pintoras o escultoras de relativo éxito, fue similar aun en grupos con diferentes posicionamientos ideológicos pero comprometidos con la cuestión femenina. En rigor, muchas de las animadoras de estos movimientos pertenecientes a capas medias y altas de la sociedad compartían una misma formación e imaginaron similares posibilidades para las mujeres en el gran arte. Sin embargo, como sugeriremos, fueron los "otros feminismos" no liberales, según la expresión de Hutchison (2001: 8), ${ }^{3}$ los que otorgaron mayor importancia a la promoción de la obrera artista, la trabajadora calificada en oficios artísticos, un auténtico topos de la época (SCOCCO, 2008: 215).

Los objetivos de este trabajo son analizar el pensamiento femenino en torno a las artes, contextualizando estos debates en el marco más amplio de las discusiones sobre el trabajo remunerado de las mujeres y sus capacidades intelectuales, a partir de tres episodios y debates donde movimientos de mujeres y prácticas artísticas se entrecruzaron: la Exposición Feminista de 1898, los congresos y asociaciones de mujeres en torno a 1910 y las páginas de la revista Unión y Labor. El análisis de los mismos ilumina aspectos hasta ahora inexplorados sobre el modo en que se concibieron las relaciones entre mujer y arte en la Buenos Aires de la modernización.

\section{Educar a la soberana}

7 Los proyectos del Consejo Nacional de Mujeres (CNM) y de la Asociación de Universitarias Argentinas (AUA), frecuentemente presentados como antagónicos, ${ }^{4}$ poseen importantes puntos de consenso en el terreno de la educación femenina, un problema que ocupó a las mujeres comprometidas de entresiglos. El CNM fue una asociación de diversos grupos que cubría gran parte del país. Fundado en 1900 a instancias de Cecilia Grierson, primera médica argentina, fue paulatinamente convirtiéndose en una sociedad filantrópica, al tiempo que entabló vínculos con grupos de extrema derecha. Sosa de Newton ha señalado que "no salió a la palestra de manera combativa para reclamar por los derechos femeninos sino que trabajó mucho en el aspecto cultural". (2007: 144). La AUA tenía un perfil más renovador y la figura de Cecilia Grierson, ya distanciada del CNM, fue central. Ambas agrupaciones realizaron eventos para conmemorar el Centenario de la Revolución de Mayo de 1910. El Primer Congreso Patriótico de Señoras en América del Sud, organizado por el CNM, contó con 
el apoyo oficial de la Comisión del Centenario y recibió una amplia cobertura por parte de los diarios contemporáneos. Mientras el Congreso Patriótico se presentó como un homenaje a las llamadas patricias argentinas, el Congreso Femenino, realizado por la AUA, se planteó como objetivo explícito la discusión de la situación contemporánea de las mujeres y la reflexión acerca de los derechos cívicos. Dora Barrancos ha demostrado la existencia de vínculos entre estos grupos, relativizando las fronteras que los separarían (2002: 26-27). Además, ha resumido la complejidad de este modo: "el Consejo reunía a las mujeres más conservadoras, y en alguna medida ligadas a la Iglesia, no faltaban en sus filas las que exhibían sensibilidad social y preocupación por la condición de las trabajadoras" (2008: 12).

En el marco del Primer Congreso Femenino, Elicenda Parga, directora de la Escuela Profesional Superior de Santiago de Chile y representante del gobierno chileno, llamó la atención acerca de la importancia de la "formación de las hijas del pueblo" (2008 [1910]: 110). La educación de las muchachas de clases bajas, que se suponía debía ser eminentemente práctica, ${ }^{5}$ fue central en los proyectos discutidos en este encuentro.

En el Primer Congreso Patriótico de Señoras en América del Sud se repitieron las preocupaciones en torno a la necesidad de reformar la educación femenina. La mujer preparada era indispensable como "elemento de trabajo, de aptitudes y de estudio" (PRIMER CONGRESO..., 1910: 10). Ella debía ser capaz primordialmente de bastarse a sí misma, un atributo que la distinguía de las otras mujeres, las incultas -aquellas que nada provechoso producían-, y también, y este punto es asimismo crítico, de las que no lo necesitaban. ${ }^{6}$ Ahora bien, existía el peligro latente de que los deberes femeninos fueran olvidados. La tendencia más conservadora del movimiento de mujeres no podía resolver este conflicto más que de una manera: las nuevas actividades desarrolladas por la mujer sólo tenían que reafirmar su rol pretendidamente natural de educadoras y encargadas del hogar. Esta misión doble, alabada de mil maneras, constituyó el argumento desplegado por este grupo para justificar su adhesión a la integración, siempre moderada, de las mujeres a la esfera pública del trabajo y la educación.

Diferentes presentaciones realizadas ante el Congreso Patriótico defendieron el cambio en la educación de las mujeres. Julia Moreno de Moreno, quien más tarde sería presidenta del CNM, expresaba que el "problema trascendental de la educación de la mujer" era un tópico recurrente en sus reflexiones (MORENO DE MORENO, 1910: 122). Este asunto constituía un problema, precisamente porque ponía en riesgo aspectos centrales de la organización social. Es por eso que Moreno distinguía entre educación e instrucción. La instrucción se vincula con el desarrollo de la inteligencia, mientras que la educación tiene como propósito estimular los sentimientos. La educación femenina permitiría a la mujer ejercer su rol natural dentro de la sociedad, papel que exigía de ella modestia, laboriosidad y abnegación (MORENO DE MORENO, 1910: 123-124).

11 Las ideas en torno a los conocimientos útiles y necesarios para las mujeres remiten a uno de los temas más transitados por el pensamiento de estos grupos femeninos: las ciencias domésticas, un conjunto nunca del todo explicitado de normas científicas para la formación y dirección del hogar. ${ }^{7}$ La reflexión sobre este tema fue un punto de convergencia para los movimientos de mujeres y la creación de la "Escuela de las Madres" (IRIBARNE DE PITA, 1910: 192-200) se tornó acuciante. La educadora Rosario Vera Peñaloza, por ejemplo, enumeró qué conocimientos científicos debían ser adquiridos por las dueñas de casa: fisiología de los niños, prácticas higiénicas y primeros auxilios, entre otros. Ahora bien, un elemento sorprendente en esta 
enumeración es la necesidad de conocer el arte "de embellecer el hogar" (1910: 133). Las labores integran, de este modo, una parte de una auténtica y completa educación en femenino.

Esta formación podía llevarse aún más lejos, constituyendo una profesión y transformando a sus practicantes en "obreras artistas" según una elocuente expresión contemporánea que ponía de relieve la pertenencia de este tipo de trabajadoras a clases modestas (LA NACIÓN, 1894: 3). La necesidad de instruir a las futuras madres y esposas, que eran también potenciales trabajadoras remuneradas, fue un asunto atravesado por las diferencias de clase. En realidad, eran las mujeres de orígenes modestos las que debían ser especialmente formadas para desempeñar estos roles. Y en esta misión la tarea de las mujeres acomodadas era crucial. La "distinguida educacionista francesa" Gabriela Meillon opinaba que las señoritas ricas tendrían que interesarse por las "humildes y simpáticas" alumnas de las escuelas profesionales, sobre todo la antigua Santa Marta, adquiriendo los productos allí realizados y realizando donaciones para sostener estos emprendimientos (1910: 212). Iribarne de Pita, a cargo de la escuela de la Sociedad Santa Marta, agregaba que las mujeres ricas debían invitar a las estudiantes a "sus lujosas moradas, para que viendo ropas y adornos lindos y artísticos puedan inspirarse para crearlas á su vez" (1910: 213). En realidad, podemos suponer que el gusto femenino era patrimonio exclusivo de las mujeres pertenecientes a las clases privilegiadas. Sobre ellas parecía pesar la difícil tarea de educar estéticamente a las mujeres de clases inferiores.

Decir que las porteñas de clase acomodada poseían naturalmente "buen gusto" y "nativa elegancia" se convirtió en un auténtico topos apropiado aun por las feministas como Elvira López (LÓPEZ E. V., 1902: 33). Unos años antes de la eclosión de estos debates, en 1898, un grupo de damas de la alta sociedad había ensayado una presentación de los talentos artísticos apropiados para su sexo con ocasión de la Exposición Nacional.

\section{Una ocasión distinguida: la Exposición Nacional de 1898}

14 La "Sección Feminista" de la Exposición Nacional, ${ }^{8}$ sin ser la primera de su género, marcó un punto saliente en la visibilización de las actividades artísticas consideradas apropiadas para las mujeres, tomando como claro antecedente la World's Columbian Exposition, ${ }^{9}$ realizada en Chicago en 1893, donde los trabajos femeninos ocuparon un edificio propio. Organizada por protectoras del Patronato de la Infancia, muchas de las cuales integrarían más tarde el CNM, buscaba sumar a las mujeres a la demostración de progreso que estos eventos aspiraban a constituir.

Según Barrancos, las mujeres de la élite que tuvieron a su cargo la organización de este espacio introdujeron el término feminista en Buenos Aires, despojando la noción de los elementos que denunciaban sometimiento y reclamaban derechos (2005). Asimismo, Barrancos ha señalado que los objetos exhibidos "revelaban un modo de ser que no discutía los valores patriarcales" y "referían a una condición que no hallaba disenso" (2005). ${ }^{10} \mathrm{Si}$ bien es indudable que hubo sectores que formaron y leyeron de este modo la Sección, creemos que es posible sugerir otros sentidos, que nos proponemos explorar. 

labores de diverso tipo y pinturas, así como también sus dotes como coleccionistas refinadas. Aunque indudablemente ambigua, como señaló Barrancos, la exhibición brindó una oportunidad para que muchas mujeres vieran salir de su hogar sus producciones, que ingresaron a una esfera pública de reconocimiento y discusión. El evento estuvo rodeado de dudas e incertidumbres. Diversas fuentes indican que había una desconfianza general hacia las capacidades organizativas de las mujeres de la élite. Se sostenía que "las damas organizadoras fracasarían en sus esfuerzos por falta de ambiente propicio y carencia de estímulo entre las familias" (LA NACIÓN, "Notas sociales. Exposición femenina": 1898: 5).

Los mil quinientos objetos exhibidos en la Exposición Feminista abarcaron bordados, encajes y muebles, caracterizados como "labores propias de la mujer" (EXPOSICIÓN NACIONAL DE 1898. REVISTA OFICIAL SEMANAL ILUSTRADA, 1898: 30), así como pinturas sobre los más diversos soportes. Asimismo, las participantes tuvieron la oportunidad de mostrar cuidados conjuntos de objetos. abanicos, marfiles, naipes de plata, utensilios de plata, encajes tejidos, muebles y peinetones. ${ }^{11}$ Se ponía en escena, de este modo, un mundo doméstico refinado cuya función sería, como hemos visto, la educación estética de las mujeres menos favorecidas. Al respecto, Teodelina Alvear de Lezica, presidenta de la comisión organizadora, señaló que "[l]as colecciones de objetos de arte... despiertan y estimulan el sentimiento del buen gusto" (EXPOSICIÓN NACIONAL DE 1898. REVISTA OFICIAL SEMANAL ILUSTRADA, 1898: 378). La venta de abonos para "señoras y señoritas" y la gratuidad hasta las dos de la tarde reforzaban la misión pedagógica del evento (LA NACIÓN, “Notas sociales. Exposición Feminista”: 1898: 5).

19 Junto a los trabajos realizados por mujeres de la élite, fueron exhibidos labores de jóvenes asiladas en instituciones de caridad, estudiantes de escuelas profesionales y tejedoras de diversas provincias (EXPOSICIÓN NACIONAL DE 1898. REVISTA OFICIAL SEMANAL ILUSTRADA, 1898: 314; EXPOSICIÓN NACIONAL DE 1898. REVISTA OFICIAL SEMANAL ILUSTRADA, 1898: 378). Se buscaba demostrar la "notable aptitud" de las mujeres argentinas, cuyos talentos rivalizaban con los modelos europeos (EXPOSICIÓN NACIONAL DE 1898. REVISTA OFICIAL SEMANAL ILUSTRADA, 1898: 378). El poner lado a lado trabajos ejecutados por mujeres de clases tan diversas ponía de manifiesto -y esto se planteó de modo explícito- la acción civilizadora de las sociedades filantrópicas sostenidas por la élite. Las clases privilegiadas actuaban como garantes del gusto exhibido por las jóvenes de clases medias y bajas que se formaban en oficios artísticos. Significativamente, los ciento setenta y seis premios distribuidos fueron otorgados en general a damas de la élite (EXPOSICIÓN NACIONAL DE 1898. REVISTA OFICIAL SEMANAL ILUSTRADA, 1898: 382-384).

La prensa feminista saludó el acontecimiento, incorporándolo al movimiento tendiente al progreso femenino. Por ejemplo, Clorinda Matto de Turner expresó:

El uso que se ha introducido en los centros civilizados de realizar exhibiciones públicas que alienten al industrial é impulsen al obrero, ha tenido en el presente año grata resonancia para la mujer, pues, en la Exposición Nacional Argentina, la sección femenina es una de las que más ha atraido la atención de los visitantes y la que ha provocado esa noble emulación hija del entusiasmo, pequeña causa que, en el corazón femenino, es generador de los grandes efectos (1898: 340). 

los sectores más diversos del movimiento de mujeres. Resultaba claro que la educación de las jóvenes era de especial importancia en casos donde tuvieran que bastarse a sí mismas y participar de la lucha por la vida. 
El énfasis en la necesidad de brindar a las mujeres herramientas para ser económicamente independientes aparece con fuerza en el acta de instalación de la Sociedad de Beneficencia (1823), institución dirigida por mujeres de la élite. Allí, Bernardino Rivadavia expresó que el ejercicio "de la industria en las mujeres, haría que ellas dieran el producto que no dan ahora, y que adquirieran por sí mismas los medios de su subsistencia; porque la preocupación que cree serle esto imposible á la mujer, debe ser atacada con valor y vencida con firmeza" (citado en CORREA LUNA, 1923: 70). No sorprende entonces que mujeres de la élite pertenecientes luego al CNM -herederas simbólicas del legado de las mujeres de la Sociedad-, fundaran la primera escuela profesional para mujeres, la Escuela Profesional de Mujeres de la Sociedad Santa Marta, en 1895(ETTERSBERG, 1898: 4; cfr. GUERRICO y SALA, 1902: 16). Esta institución presentaba grandes similitudes con las écoles professionnelles francesas, donde el dibujo ocupaba un rol secundario y servía de base para el aprendizaje de las artes decorativas, consideradas apropiadas para las mujeres de condición humilde que la escuela recibía (SCOCCO, 2008: 213). Su programa abarcaba los siguientes módulos:

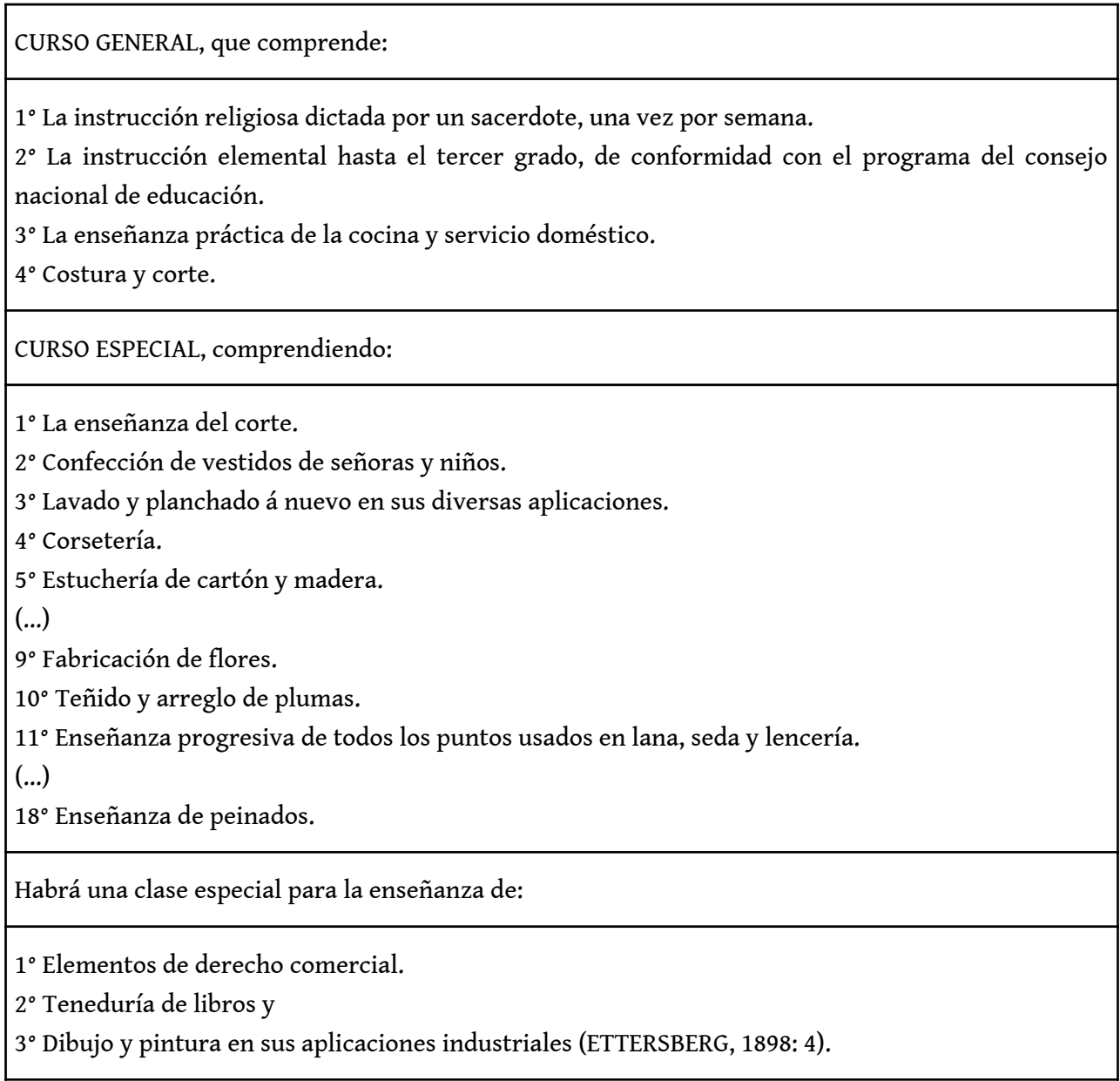

El programa fue realizado según los consejos de Josefa Aguirre de Vassilicós (1838-1913, una escultora de cierto renombre y gran participación en diversas sociedades benéficas, quien había visitado un número importante de instituciones de esta clase durante su estadía en Europa: "[Aguirre] indicó que podrían fundarse Escuelas Profesionales á imitación de las que había visitado en Francia y que tenían por objeto dar á la mujer 
pobre una educación práctica que le sirviera para ganar honradamente la vida" (ETTERSBERG, 1898: 4). La escultora era un auténtico referente en el terreno de la llamada educación industrial y de hecho al menos hasta 1900 no hubo otra escuela de este tipo. Las labores femeninas ocupaban un lugar destacado en este programa: "bordados en blanco, color y oro, festones, marcas" eran centrales (LA NACIÓN, "Notas sociales", 1896: 5).

Los proyectos propiciados por mujeres pertenecientes o cercanas a la AUA eran diferentes. En 1910 Ernestina López, refiriéndose a las escuelas profesionales existentes, proponía:

reemplazar ciertos talleres como los de guantes, flores y lencería, por otros, en los cuales se diera impulso a las que podríamos llamar industrias nacionales femeninas como ser el tejido de mantas, ponchos y randas, el trenzado de la paja y el cuero, la conservación de frutas y la repostería, ocupaciones que en las provincias del interior constituyen los medios de vida de casi todas las mujeres de clase pobre (LÓPEZ E. A., "Las industrias", 2008 [1910]: 123).

Se podía, por lo tanto, aprovechar el saber hacer de estas mujeres, siempre y cuando se mejorara su productividad. Pero también se tornaba necesario dotar a las mujeres "del gusto artístico" del que carecían, regresando a la misión pedagógica (LÓPEZ E. A., "Las industrias ...", 2008: 123).

31 Desde el CNM se difundió la idea de que las habilidades manuales desempeñaban un rol relevante en la constitución de una identidad femenina, que también estaba estrechamente vinculada a la creciente incorporación de las mujeres al trabajo asalariado. Lapalma de Emery trazó una breve historia de las labores en Argentina:

Verdad es que en oposición á lo que sostienen algunos, hubo entonces entre las damas argentinas infinidad de ellas que fueron muy hábiles en la confección de labores femeninas, como igualmente en el ejercicio de pequeñas industrias, pero todo esto, realizado por vía de entretenimiento y sin tener en cuenta ningún interés económico de importancia...(1910: 142)

Desarrolladas por o más allá de los intereses pecuniarios, las artes femeninas, realizadas en el seno del hogar en ambos casos, formaron parte de la identidad adjudicada a las mujeres argentinas de todas las clases sociales por las participantes de los movimientos de mujeres. En su presentación ante el Congreso Patriótico, Pujato Crespo señaló que otrora se temía que "la mujer escritora perdiera su encanto natural, que descuidara el arreglo de su hogar, las labores de mano" (1910: 159).Las manualidades aparecen, entonces, completamente integradas a un modelo de feminidad basado en lo doméstico pero susceptibles de ser incorporadas a un modelo productivo. La intervención de Champy Alvear, autora de libros de enseñanza de dibujo para escuelas, en el Congreso Femenino vuelve sobre estos temas. Es la naturaleza delicada y sensible de las mujeres las que las torna especialmente aptas para el arte. Pero dado que el lugar por excelencia de la mujer es el hogar, sus tendencias hallan en él un lugar privilegiado para dar rienda suelta a su creatividad. La tarea de "embellecer el templo donde se educa la infancia", labor que la convierte en una "verdadera hada de la casa", sólo es posible con educación estética. Las facultades de la imaginación así cultivada podrían trasladarse a la estética y a la industria, superando los límites del hogar. Tras la lectura de este texto, el Congreso Femenino se pronunció a favor de la educación estética de la mujer, al tiempo que se manifestó la preocupación porque este tipo de formación condujera al amor al lujo (CHAMPY ALVEAR, 2008 [1910]: 143-7). 
También Cecilia Grierson, de la AUA, advirtió sobre este peligro, haciendo notar que "cocina, lavado y planchado" eran ramas más útiles que los "puntos de aguja para 'adorno"' (GRIERSON, 2008 [1910]: 184). Grierson atacaba de este modo a uno de los más queridos proyectos de la filantropía femenina de entresiglos: la escuela Santa Marta. La "tendencia estética", demostrada por la preponderancia de "los ramos de adorno y lujos", que Grierson achacaba a estas iniciativas, era blandida como argumento en favor de la modernización de los planes de estudio.

Para Grierson, a pesar de su apoyo a ciertos artistas, la formación de obreras artistas no era un objetivo. La escuela práctica de economía doméstica debía ante todo "[h]acer sirvientas aptas y sobre todo con conocimientos prácticos" (RUTH, 1899: 5). ${ }^{17}$ Como la defendida por muchos de sus contemporáneos, la educación que Grierson propiciaba tendía a cubrir "la habitación", "la alimentación y cuidados personales", la "puericultura y educación de los niños" y "la práctica de cocina". El objetivo era doble: manejar un hogar y, muy secundariamente, trabajar fuera del ámbito doméstico (cfr. GRIERSON, 2008 [1910]: 185). ${ }^{18} \mathrm{El}$ "verdadero trabajo manual de la muger [sic]" debía estar en relación con "el rol principal de la muger [que] es dentro del hogar" (GRIERSON, 1896).

5 La Escuela Santa Marta tenía esos mismos objetivos pero el aspecto laboral estaba subrayado:

“La enseñanza completa de las escuelas profesionales durará tres años, y como en los establecimientos de la misma índole que existen en algunas capitales europeas, en ellas se enseñará á cocinar, planchar, coser, bordar, corte de vestidos y demás conocimientos prácticos que complementan la educación de la mujer, y con los que podrá hallarse en condiciones de ganarse honradamente la vida" (LA NACIÓN, "Notas sociales", 1896: 5).

En efecto, para 1904 se dictaban clases comerciales y dactilografía. El discurso de inauguración de la escuela Santa Marta no deja dudas en torno a su fin: crear "la obrera mañana, la mujer, madre virtuosa y abnegada capaz de luchar contra las seducciones tentadoras del mal ejemplo" (PODESTÁ, 1896: 3). Una enseñanza doblemente condicionada por el género y la clase, como señaló Manuel Podestá en la inauguración, pero que sin embargo ponía en pie de igualdad el valor del trabajo dentro y fuera del hogar.

Por otro lado, ciertos grupos se abocaron a la tarea de facilitar la inserción laboral de las obreras artistas, a través de diversas asociaciones considerablemente lejanas al feminismo y en ciertos casos asociadas al CNM. El Woman's Exchange fue una iniciativa análoga a otras existentes en Estados Unidos e Inglaterra. Sus socias pertenecían a lo más selecto de las comunidades inglesa y estadounidense. Esta institución, cuyo salón anual era detalladamente cubierto por la prensa, tenía como fin "ayudar á la mujer necesitada á procurarse los medios de vivir honradamente, por medio de la venta de sus propias obras y labores manuales, de calidad y mérito artístico mejorados por una práctica bien dirigida y reglamentada" (LA NACIÓN, 1897: 5). Allí podían comprarse"confecciones de ropa interior y exterior, bordados, encajes, muñecas vestidas, artículos de modista, objetos de fantasía, pinturas, dibujos, esculturas, tortas, frutas conservadas, jaleas, confites" (L. V. E., 1898: 2). Se buscaba sobre todo lograr una remuneración más justa que la ofrecida por las grandes tiendas, con una acción directa. Estas asociaciones combinaban la acción filantrópica hacia mujeres desfavorecidas con la autoridad de clase sobre la cultura. 


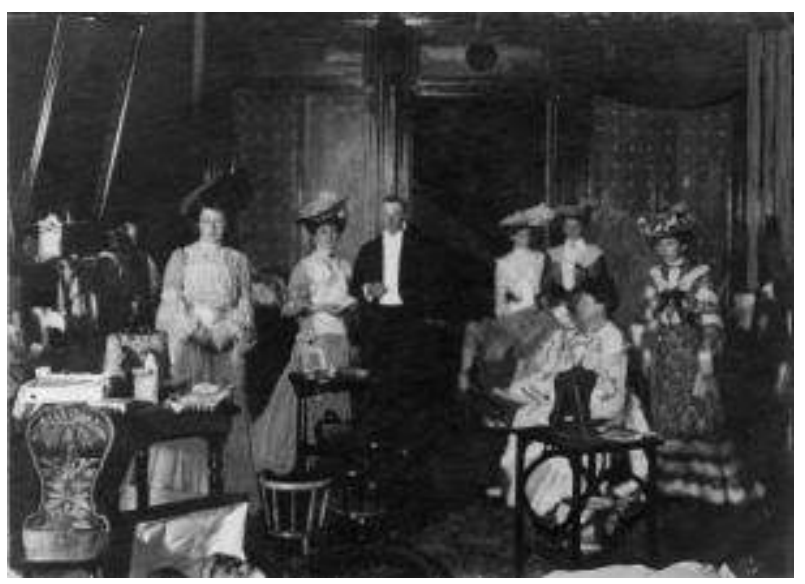

Departamento de Documentos Fotográficos, Archivo General de la Nación (Buenos Aires, Argentina)

Las artes femeninas, asociadas con la vanidad y el lujo por la austeridad del primer feminismo, eran reivindicadas por los "otros feminismos" como una vía posible hacia la independencia económica y el progreso social de las mujeres. Esta vía, de objetivos quizás más conservadores y de menor impacto social -sobre todo comparada con el acceso a las profesiones liberales promovido por la AUA-, no dejaba ofrecer modestas posibilidades de emancipación. Tanto el CNM como la AUA entablaron un debate sobre el rol de la mujer moderna, los espacios permitidos y vedados a ella y las actividades apropiadas para su condición.

\section{Imágenes de artistas faro en la prensa periódica}

La abundante prensa feminista demostró un interés decidido por un grupo reducido de artistas, tanto argentinas como extranjeras, en el marco de la creciente cobertura del mundo artístico parisino. A pesar del importante número de mujeres artistas activas entre fines del siglo XIX e inicios del XX,19 las referencias a estas personalidades individuales son comparativamente escasas. Por ejemplo, Búcaro Americano, revista de aparición irregular entre 1896 y 1908, desarrolló en sus páginas relevantes debates en torno a la mujer como "obrera del pensamiento". Sin embargo, las artes visuales ocuparon un espacio reducido en su proyecto de ilustración femenina. Durante sus doce años de publicación, apenas se refirió a tres artistas: Sofía Posadas, Lola Mora y Josefa Aguirre de Vassilicós. ${ }^{20}$ Las trayectorias de María Obligado de Soto y Calvo, Julia Wernicke $u$ Hortensia Berdier, entre otras, fueron en cambio completamente ignoradas. 21

Si bien la figura de la moderna mujer artista fue difundiéndose por la prensa y la literatura de modo sostenido desde la década de 1890, no resultaba extraño toparse con discursos netamente descalificadores. Por ejemplo, un suelto de una revista afirmaba en 1894 que la mujer alcanzaba sin dificultades cierta maestría en diversas ramas del arte pero que raramente los dominaba. El articulista, citando a cierto arzobispo Whately, se apresuraba a aclarar que la educación poco tenía que ver en este proceso. La prueba irrefutable la constituía el hecho de que pocas mujeres se destacaran en el arte y la música: "Así son mas las mujeres que los varones que aprenden música y 
pintura y muchas alcanzan bastante éxito; pero los grandes pintores y compositores son casi todos varones". En resumidas cuentas, las mujeres carecían de "facultad inventiva" (BRIC-À-BRAC, 1894: 589).

Ernestina López llamó a dejar de lado las teorías que sostenían la inferioridad intelectual de las mujeres, al tiempo que reconocía que era "un hecho probado que el intelecto femenino, no ha dado en las ciencias, las letras, las industrias y las artes, un número equivalente de genios, al que ha dado el del hombre" (LÓPEZ E. A., 2008 [1910]: 64). A medida que la cobertura periodística de las novedades artísticas de Francia se hizo más exhaustiva -y con ella la presencia de noticias y datos referidos a las mujeres artistas-, la prensa feminista profundizó su interés en este asunto. El arte llegó a ser visto como uno de los tantos dominios donde la agencia femenina era ignorada: "Las mujeres que pugnan por difundir los altos ideales artísticos, o por propiciar entre los demás estudios serios, se quejan de la indiferencia con que se reciben sus esfuerzos y de la fría acogida que se hace a sus producciones" (LÓPEZ E. A., 2008 [1910]: 59).

Interesa particularmente señalar aquí la presencia permanente de Rosa Bonheur, que adquirió una notoriedad impactante a pesar de las múltiples desviaciones que suponía al orden de diferencia sexual. ${ }^{22}$ Tanto su obra como su vida fueron examinadas en las publicaciones periódicas de Buenos Aires, sumamente funcionales en el proceso de difusión de un modelo de mujer artista celebrada.

Fue la muerte de Rosa Bonheur el episodio que brindó ocasión para las reflexiones más interesantes. La Columna del Hogar publicó un extenso artículo. Allí se definía a Bonheur como "una de las mujeres que más han honrado á nuestro sexo" (LA COLUMNA DEL HOGAR, "Rosa Bonheur", 1899: 9). Uno de los episodios más interesantes de los relatados en esta crónica se refiere a los comienzos de su trayectoria artística. Bonheur había fracasado como aprendiz de costurera y como profesora en un internado. No obstante, en "la tranquilidad del hogar y del estudio, la verdadera tendencia de su espíritu no tardó en manifestarse". Sus progresos fueron tales que su padre decidió enviarla al Louvre a copiar obras. Luego, el Castillo de By reemplazaría la casa paterna como lugar de reflexión y retiro. El aislamiento y la domesticidad ocuparon en esta elegía un lugar destacado. La semblanza biográfica de La Columna del Hogar está adaptada del capítulo dedicado a Bonheur dentro de la monumental obra de Elizabeth Fries Ellet, Women Artists in All Ages and Countries. La selección del original resulta singular: en el texto de Ellet se presenta un retrato de Bonheur como "wild, active, impetuous child, impatient of restraint, and having a detestation of study" (ELLET, 1859: 261). Poco queda de esta descripción, aunque sí permanece la idea de determinación que atraviesa el texto de Ellet. Bonheur era simultáneamente un modelo de gran artista y una mujer doméstica. El sencillo dibujo que acompañó el texto no ocultó la vestimenta masculina que Bonheur solía utilizar, entendiéndolo posiblemente como una transgresión permitida en el ámbito doméstico donde la artista producía. 


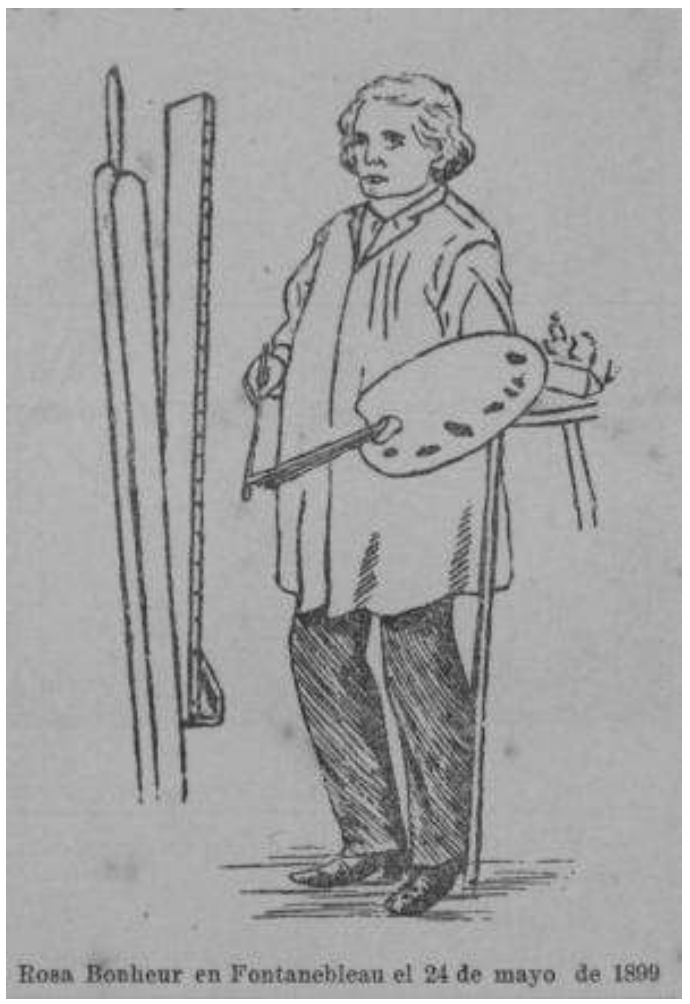

Museo Histórico Sarmiento (Buenos Aires, Argentina)

En el cambio de siglos, la reflexión en torno a las posibilidades de las mujeres en el campo del arte fue llevada a cabo en la Revista del Consejo Nacional de Mujeres de la República Argentina y en La Columna del Hogar. En estas publicaciones coexistieron la celebración de artistas como Lola Mora (GLUZMAN, 2013a) y la defensa de diversos oficios manuales de carácter artístico, un aspecto que -como hemos visto-, fue marginado por el feminismo liberal. En las páginas de la revista del CNM se desplegó un rico panorama de artistas, como Lola Mora y Dolores Alazet Rocamora, y de actividades artísticas femeninas, como la miniatura. Estos textos informaban a las suscriptoras acerca del progreso de las mujeres, al tiempo que daban a conocer oficios que podían realizarse sin riesgos para el honor. Pero sobre todo estas representaciones ofrecían al creciente número de lectoras "modelos, ejemplos inspiradores y estrategias útiles" (CHERRY, 1993: 26).

La fascinación por ciertas personalidades -auténticas artistas faro capaces de señalar el camino del progreso-, también apareció con fuerza en las páginas de la revista Unión y Labor, editada por la agrupación homónima, representada en el Congreso Femenino de 1910 por la artista francesa Andrée Moch y por Margarita Rothkoff. Esta asociación de mujeres socialistas y feministas, comprometidas con el mejoramiento de las condiciones de vida de mujeres y niños (Lavrin, 1995: 104), editó una cuidada revista desde 1909.

A diferencia de otras revistas feministas donde el arte ocupó un sitio restringido, Unión y Labor incluyó crónicas y reproducciones artísticas de modo permanente, haciendo un uso de la imagen más intenso que ninguna publicación feminista hasta ese momento. 
Esta presencia debe ser relacionada con la participación de Andrée Moch, radicada en Buenos Aires desde 1908.

Unión y Labor se propuso crear una galería de mujeres notables (como ya había hecho $E l$ Búcaro Americano diez años antes), cuya primera integrante fue la médica y educadora italiana Maria Montessori. La publicación de artículos referidos a mujeres artistas contemporáneas había comenzado a inundar la prensa periódica ilustrada desde la década de 1890, difusión que debe ser también comprendida en el marco de la creciente participación femenina en el arte. Pero en Unión y Labor adquirió matices explícitamente feministas. ${ }^{23}$

Nos detendremos en otra de las portadas de esta revista, dedicada a Lucienne Antoinette Heuvelmans (1885-1944). Heuvelmans fue la primera ganadora del Prix de Rome, uno de los reconocimientos centrales del sistema académico francés. En 1903, tres años después del establecimiento de talleres para mujeres en la École des Beaux-Arts parisina, se autorizó la participación femenina en el Prix de Rome. Finalmente, en 1911 una mujer obtuvo esta distinción (SAUER, 1990: 36). La escultora realizaba el anhelo más profundo de toda una generación de mujeres artistas nucleadas en la Union des femmes peintres et sculpteurs y particularmente de Mme Léon Bertaux. En efecto, Heuvelmans reconocía el enorme rol que Mme Léon Bertaux había jugado en su triunfo artístico (LEPAGE, 1912: 262).

Portada de Unión y Labor, Buenos Aires, 1911

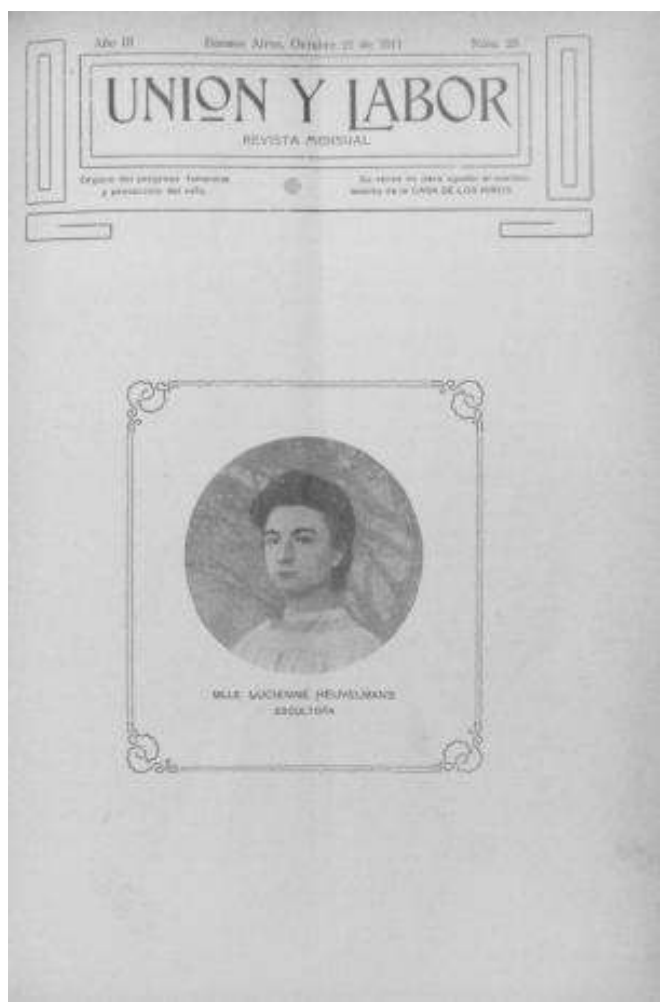

Biblioteca del Museo Saavedra (Buenos Aires, Argentina)

Completamente olvidada y desplazada de los textos canónicos del arte argentino, Moch fue una escultora, pintora y escritoranacida en Francia y llegada a Buenos Aires en 1908. Su objetivo era obtener alguno de los encargos escultóricos realizados en torno al Centenario de la Revolución de Mayo. La artista nació en 1879, en el seno de una familia 
acomodada. Habiendo recibido lecciones de dibujo entre los quince y los dieciocho años, Moch decidió dedicarse a la práctica artística como profesión tras la muerte de su padre. La artista fue educada en dos escuelas públicas de enseñanza de arte en París y Burdeos, hasta hacía poco vedadas a las mujeres. Luego de varios años de estudios, se trasladó a España y, finalmente, a América. En Buenos Aires desarrolló una intensa actividad en los campos del arte, del periodismo y de la política hasta su muerte en 1953.

50 Su autobiografía, posiblemente el primer relato extenso en primera persona de una artista activa en Buenos Aires, es rica en detalles sobre su formación. La decisión de Moch de dedicarse profesionalmente al "Arte puro", en sus palabras, coincidió con la apertura de la École. La artista comenzó sus estudios en Burdeos y luego se trasladó, con una beca, a París (MOCH, 1939: 66-67). En su autobiografía, Moch ha descrito tanto la oposición de su familia a que continuara sus estudios artísticos en París, lejos del hogar materno, como la segregación operada sobre las novatas estudiantes al interior de las instituciones educativas.

51 En efecto, uno de los pocos momentos en los que hombres y mujeres compartían espacio de trabajo era durante los concursos: "[e]n esos concursos se notaba la rivalidad. Mis compañeras se quejaban que al ir, con sus enormes compases de escultoras, a tomar las medidas sobre el modelo... los competidores masculinos les ponían trabas y buscaban la manera de hacerles perder unos minutos" (MOCH, 1939: 122).

52 Moch, en el texto que celebra la obtención del Prix de Rome por Heuvelmans, recupera los debates parisinos y el reclamo de un nuevo espacio para las mujeres en el gran arte. La artista sostiene que "[l]as mujeres acaban de conquistar una brillante victoria sobre la "Tradición"' (MOCH, 1911: 3), trasladando al ámbito porteño los intensos debates que rodearon la entrada de las mujeres al sistema académico. Sus palabras traen a la memoria aquellas de Mme Léon Bertaux: "Être prix de Rome! à part la preuve d'aptitudes pour le grand art, cela signifie... avoir dans l'Ecole des Beaux-Arts une famille qui vous prend en tutelle... vous soutient d'abord, vous encourage ensuite et vous protège toujours" (citado en SAUER, 1990: 36).

Otras heroínas celebradas en Unión y Labor fueron Lía Gismondi y la francesa Clémentine-Hélène Dufau, que se sumaron a la pequeña lista de artistas faro, la primera de las cuales había sido Bonheur.

\section{Conclusiones}

Los oficios creativos femeninos fueron asunto de reflexión en la Buenos Aires de entresiglos. Los movimientos de mujeres no se mantuvieron al margen de estos debates. Las mujeres comprometidas con cuestiones sociales desarrollaron proyectos educativos y elaboraron discursos laudatorios en torno a un grupo reducido de artistas, cuyas trayectorias constituían una prueba de las excelentes condiciones de las mujeres para el arte y un cuestionamiento a la arraigada noción de que las creaciones más elevadas escapaban a las capacidades femeninas. Carmen Champy Alvear, en su encendida defensa de la necesidad de instruir estéticamente a las mujeres desde su infancia, deslizaba los nombres de la francesa Louise Élisabeth Vigée Le Brun y de la argentina Sofía Posadas entre los de Leonardo, Rafael, Rubens, David, Greuze, Ballerini o Reynolds (2008 [1910]: 144). Las artistas faro eran intensamente anheladas, ya que 
entrañaban una expansión de las posibilidades disponibles para las mujeres. Grierson, al referirse al gran número de estudiantes femeninas en las academias de arte, señaló: "es de esperarse se forme alguna artista en escultura ó pintura" (1902: 171).

Sin embargo, las artes femeninas recibieron valoraciones diversas al interior de los movimientos de mujeres. Los sectores más conservadores abogaron por una práctica tanto doméstica como profesional de las artes femeninas, un concepto expandido que abarcaba las bellas artes $\mathrm{y}$ las artes aplicadas. Estas actividades aparecieron frecuentemente fundidas, a la vez que de manera sistemática se planteaba la necesidad de que las mujeres frecuentaran su práctica a fin de contar con un ingreso económico. Junto a las tradicionales ideas de laboriosidad, los nuevos debates en torno a las artes femeninas intentaron hallar un lugar para estas habilidades socialmente valoradas en el mejoramiento de las condiciones de vida de las mujeres. Este aspecto parece haber sido desatendido durante los primeros años de la Academia Nacional de Bellas Artes, al no existir cursos de "Artes Decorativas é Industriales" para mujeres (COLLIVADINO Y GHIGLIANI, 1910: 169). ${ }^{24}$

Fue sobre todo desde el ala más conservadora del movimiento de mujeres que se promovió el ideal de artista obrera, que equiparaba "la pintura y otros trabajos de arte" (LA NACIÓN, "Exposición Nacional”, 1898: 4) y que tenía la ventaja de poder realizarse en el hogar. Es posible que las representantes más salientes del feminismo progresista hayan desestimado la práctica de estos oficios por considerarlos peligrosamente cercanos a una imagen tradicional de la mujer y por ver en ellos la tentación del lujo. ${ }^{25}$ Al mismo tiempo que desde estos sectores se promovían ideas radicales en torno al ingreso de las mujeres a las profesiones liberales (GRIERSON, 1902: 171), el hogar fue progresivamente visto como un espacio de permanente actividad que requería de las mujeres una atención cuidadosa y que dejaba poco tiempo para actividades como el bordado. Frente a las ideas de las mujeres cercanas al CNM, las feministas presentaron otras vías más innovadoras y rupturistas para el progreso femenino, preocupación común que despertó respuestas diversas.

Fotografía de la exposición de pinturas en la Escuela Profesional de Mujeres (1906), colección particular

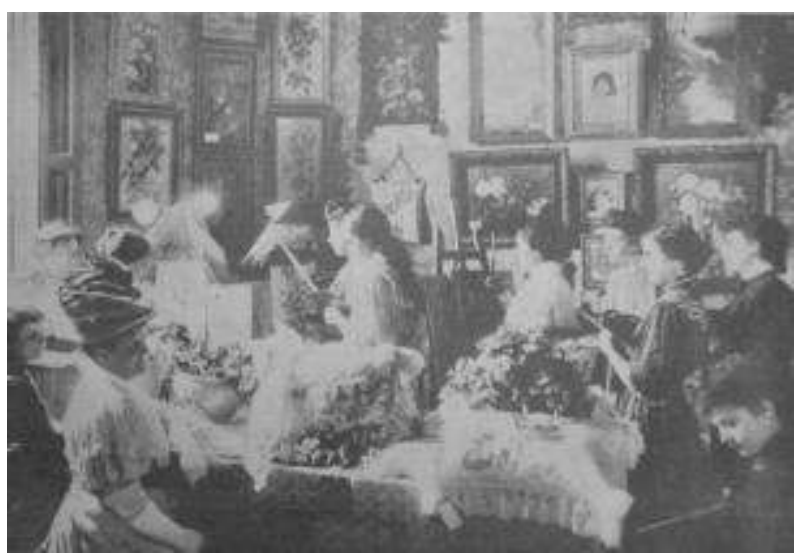

Nos interesa sugerir, a modo de conclusión, que las prácticas y representaciones emanadas de los movimientos de mujeres de entresiglos contribuyeron a la generalización de los estudios artísticos para las mujeres, que se incorporaron masivamente a la Academia Nacional de Bellas Artes y también alimentaron el alumnado de una multiplicidad de escuelas de artes, tanto oficiales como privadas. ${ }^{26}$ Por 
otro lado, este asociacionismo de mujeres encontraría una continuidad en los salones de arte femenino, desarrollados a partir de la década de 1920, precisamente en los años de afianzamiento de la profesionalización de las mujeres en el terreno del arte.

\section{BIBLIOGRAFÍA}

ARGOMEDO, M. A. (2008) [1910]. 'La moralidad y el trabajo como fin supremo de la instrucción'. En Primer Congreso Femenino (págs. 91-110). Buenos Aires: Universidad Nacional de Córdoba.

ARIZA, J. (2012). 'Artes/oficios y otras (a)sincronías de la educación artística femenina en la Argentina del cambio de siglo y más allá'. Synchronicity / Contacts and Divergences in Latin American and U.S. Latino Art (19th Century to the Present). Austin.

BALDASARRE, M. I. (2006). Los dueños del arte. Coleccionismo y consumo cultural en Buenos Aires. Buenos Aires: Edhasa.

BARRANCOS, D. (2002). Inclusión/Exclusión. Historia con mujeres. Buenos Aires: Fondo de Cultura Económica.

BARRANCOS, D. (2005). 'Primera recepción del término 'feminismo' en la Argentina'. Recuperado el 15 de junio de 2013, de Labrys: http://www.tanianavarroswain.com.br...

BARRANCOS, D. (2008). 'Introducción'. En Primer Congreso Femenino Internacional de la República Argentina (págs. 7-19). Córdoba: Universidad Nacional de Córdoba.

BRIC-À-BRAC. (1894). 'Las diferencias mentales de los dos sexos'(11 de octubre, pág. 569). Buenos Aires.

CHAMPY ALVEAR, C. (2008) [1910]. 'Importancia de la cultura estética en la educación de la mujer'. En Primer Congreso Femenino (págs. 143-147). Córdoba: Universidad Nacional de Córdoba.

CHERRY, Deborah. Painting Women. Victorian Women Artists. London, Routledge, 1993.

COLLIVADINO, P., y GHIGLIANI, A. (1910). 'La enseñanza artística en la República Argentina'. En Censo general de educación (Vol. 3, págs. 163-172). Buenos Aires: Talleres de Publicaciones de la Oficina Meteorológica Argentina.

EHRENREICH, B., \& ENGLISH, D. (1979). For Her Own Good. 150 Years of the Experts' Advice to Women. New York: Anchor Press/Doubleday.

EL NACIONAL. (1893). 'Correo del día. Congreso femenino de Chicago. Candidatas á la delegacion argentina' (28 de abril, pág. 2). Buenos Aires.

EL NACIONAL. (1898). 'Columna del hogar. Exposición femenista' (21 de octubre, pág. 2). Buenos Aires.

EL NACIONAL. (1898). 'Columna del hogar. La Exposición Feminista' (19 de octubre, pág. 2). Buenos Aires.

ELLET, E. F. (1859). Women Artists in All Ages and Countries. New York: Harper \& Brothers.

ETTERSBERG, L. V. (1898). 'Columna del hogar (sección femenina). La sociedad Santa Marta'. En El Nacional (2 de octubre, pág. 4). Buenos Aires. 
EXPOSICION NACIONAL 1898. (1898). Catálogo de la Sección Feminista. Apéndice al Catálogo General. Buenos Aires: Guillermo Kraft.

EXPOSICIÓN NACIONAL de 1898. Revista Oficial Semanal Ilustrada. (1898). 'Sección Feminista. Su inauguración' (Vol. 47, pág. 378). Buenos Aires.

EXPOSICIÓN NACIONAL de 1898. Revista Oficial Semanal Ilustrada. (1898). 'Los premios. Sección Feminista' (Vol. 48, pág. 382-384). Buenos Aires.

FREYRE De JAIMES, C. (1910). 'La acción concurrente de la mujer en el progreso no es feminismo mal entendido ni socialismo.- Cómo debemos entenderlo nosotros'. En Congreso Patriótico de Señoras en América del Sud. (págs. 247-262). Buenos Aires: Imprenta europea de M. A. Rosas. GLUZMAN, G. (2012). 'El trabajo recompensado. Discursos sobre artes y artistas en el temprano feminismo argentino (1898-1911)'. Congreso Latinoamericano de Historia de las Mujeres. Buenos Aires. GLUZMAN, G. (2013a). Feminism, art and memory in Buenos Aires at the beginning of the 20th century: the projected monument to the Argentine women of the Revolution. Senzacornice, 6. GLUZMAN, G. (2013b). 'Women and art in 19th century Buenos Aires: the French model and the case of Rosa Bonheur". Seminario L'art des révolutions (1789-1871). Montréal.

GRIERSON, C. (1896). 'Carta a Antonio Bermejo'. Copiador de cartas. Colección Cecilia Grierson. Colecciones Especiales y Archivos, Universidad de San Andrés, Argentina.

GRIERSON, C. (1899). 'La obra y la educación de la mujer argentina'. En La Columna del Hogar (20 de noviembre). Buenos Aires.

GRIERSON, C. (1902). Educación técnica de la mujer. Informe presentado al Sr. Ministro de Instrucción Pública de la República Argentina. Buenos Aires: Tipografía de la Penitenciaría Nacional.

GRIERSON, C. (2008) [2010]. 'Ciencias y artes domésticas'. En Primer Congreso Femenino (págs. 180-188). Córdoba: Universidad Nacional de Córdoba.

GUERRICO, M. de, y SALA, A. v. (1902). “Acta de la cuarta Asamblea del Consejo Nacional de Mujeres”. En Revista del Consejo Nacional de Mujeres (Vol. 6, págs. 14-22). Buenos Aires.

GUY, D. J. (2009). Women Build the Welfare State. Performing Charity and Creating Rights in Argentina, 1880-1955. Durham y London: Duke University Press.

HUTCHISON, E. Q. (2001). Labors Appropriate to Their Sex: Gender, Labor, and Politics in Urban Chile, 1900-1930. Durham y London: Duke University Press.

IRIBARNE De PITA, M. M. (1910). 'Comentario a 'Protección á las alumnas pobres de las Escuelas Profesionales', de Gabriela Meillon'. En Congreso Patriótico de Señoras en América del Sud (págs. 213-214). Buenos Aires: Imprenta europea de M. A. Rosas.

IRIBARNE De PITA, M. M. (1910). “Proyecto de fundación de la Escuela de las Madres”. En Primer Congreso Patriótico de Señoras en América del Sud (págs. 192-200). Buenos Aires: Imprenta europea de M. A. Rosas.

KAPLAN, T. (1982). Female Consciousness and Collective Action: The Case of Barcelona, 1910-1918. Signs, 7(3), 545-566.

L. V. E. (1898). 'Columna del hogar (sección femenina)'. En E. Nacional.

LA COLUMNA del HOGAR. (1899). 'A nuestros colegas' (10 de enero, pág. 1-3). Buenos Aires.

LA COLUMNA del HOGAR. (1899. 'Rosa Bonheur' (1 de junio, pág. 9). Buenos Aires. 
LA COLUMNA del HOGAR. (1900). 'Redacción. El Consejo Nacional de Mujeres' (5 de diciembre, pág. 534-535). Buenos Aires.

LA NACIÓN. (1894). 'Hombres y cosas. Obreras artistas' (24 de noviembre, pág. 3). Buenos Aires.

LA NACIÓN. (1896). 'Notas sociales' (21 de mayo, pág. 5). Buenos Aires.

LA NACIÓN. (1897). 'Woman's Exchange. Exposición anual. Su inauguración' (17 de diciembre pág. 5). Buenos Aires.

LA NACIÓN. (1898). 'Exposicion Nacional' (19 de octubre, pág. 4). Buenos Aires.

LA NACIÓN. (1898). 'Notas sociales. Exposición femenina' (14 de octubre, pág. 5). Buenos Aires.

LA NACIÓN. (1898). 'Notas sociales. Exposición Feminista' (16 de octubre, pág. 5). Buenos Aires.

LAPALMA de EMERY, C. (1910). 'El trabajo de la Mujer en la Argentina a través del Centenario'. En Primer Congreso Patriótico de Señoras en América del Sud (págs. 140-157). Buenos Aires: Imprenta europea de M. A. Rosas.

LAVRIN, A. (1995). Women, Feminism and Social Change in Argentina, Chile, and Uruguay, 1890-1940. Lincoln y London: University of Nebraska Press.

LEPAGE, E. (1912). Mme Léon Bertaux. Une conquête féministe. Une page de l'histoire de l'art au XIXe siècle. Paris: Imprimerie française - J. Dangon.

LOPEZ, E. A. (2008) [1910]. En Primer Congreso Femenino Internacional de la República Argentina (págs. 53-69). Córdoba: Universidad Nacional de Córdoba.

LÓPEZ, E. A. (2008) [1910]. 'Las industrias nacionales femeninas en las escuelas profesionales'. En Primer Congreso Femenino (págs. 123-124). Córdoba: Universidad Nacional de Córdoba.

LÓPEZ, E. V. (1902). 'La mujer en la Argentina: costumbres, educación, profesiones á que se dedica, datos estadísticos, legislación etc.' En Revista del Consejo Nacional de Mujeres (Vol. 6, págs. 33-38). Buenos Aires.

MALOSETTI Costa, L. (2000). En VI Jornadas de Historia de las Mujeres y I Congreso Iberoamericano de Estudios de las Mujeres y de Género (CD-ROM ed.). Buenos Aires: Facultad de Filosofía y Letras. Universidad de Buenos Aires.

MALOSETTI Costa, L. (2005). 'The example of Millet: the role of the press in the process of emergence of a public space for fine arts in Buenos Aires (1880-1900)'. En M. Heusser, M Hannoosh, E. Haskell, L. Hoek, D. Scott, \& P. Voogd, On Verbal / Visual Representation. Word \& Image Interactions 4 (págs. 43-52). Amsterdam y New York: Rodopi.

MALOSETTI Costa, L. (2011). 'Perspectives for Feminist Art History in Argentina'. College Art Association Annual Conference. New York.

MATTO de TURNER, C. (1898). 'Exposición Nacional'. En Búcaro Americano. Periódico de las Familias (Vols. 28-29, pág. 340). Buenos Aires.

MEILLON, G. (1910). "Protección á las alumnas pobres de las Escuelas Profesionales". En Primer Congreso Patriótico de Señoras en América del Sud (págs. 207-213). Buenos Aires: Imprenta europea de M. A. Rosas.

MOCH, A. (1911). 'Luciana Heuvelmans'. En Unión y Labor (21 de octubre, pág. 3). Buenos Aires.

MOCH, A. (1939). Andanzas de una artista. Buenos Aires: Aniceto López. 
MORENO de MORENO, J. (1910). “Acción concurrente de la mujer en la 'instrucción del pueblo' Medidas que pueden ponerse aún en práctica”. En Primer Congreso Patriótico de Señoras en América del Sud. Antecedentes (págs. 122-128). Buenos Aires: Imprenta europea de M. A. Rosas.

P.B.T. (1904). 'Primera Escuela Profesional de Mujeres 'Santa Marta" (Vol. 12). Buenos Aires.

PARGA, E. (2008 [1910]). 'Escuelas profesionales ó industriales'. En Primer Congreso Femenino Internacional de la República Argentina (págs. 110-115). Córdoba: Universidad Nacional de Córdoba.

PIAGGIO de TUCKER, J. M. (1910). 'Conclusiones'. En Primer Congreso Patriótico de Señoras en América del Sud (pág. 215). Buenos Aires: Imprenta europea de M. A. Rosas.

PODESTÁ, M. J. (1896). 'La mujer argentina. Su acción civilizadora'. En La Nación (26 de junio, pág. 3). Buenos Aires.

Primer Congreso Femenino Internacional de la República Argentina. (2008). Córdoba: Universidad Nacional de Córdoba.

Primer Congreso Patriótico de Señoras en América del Sud. (1910). 'Prólogo'. Buenos Aires: Imprenta europea de M. A. Rosas.

PUJATO Crespo, M. (1910). 'Historia de las revistas femeninas y mujeres intelectuales que les dieron vida'. En Primer Congreso Patriótico de Señoras en América del Sud (págs. 157-179). Buenos Aires: Imprenta europea de M. A. Rosas.

QUESADA, E. (1899). La cuestión femenina. Buenos Aires: Imprenta de Pablo Coni é Hijos.

Reglamento de la Escuela de Artes y Oficios de la Provincia de Buenos Aires. (1896). La Plata: Tipografía del Establecimiento.

RUTH. (1899). 'Media hora de charla con la primera doctora argentina! En La Columna del Hogar (1 de enero, págs. 4-5). Buenos Aires.

SAUER, M. (1990). L'entrée des femmes à l'École des Beaux-Arts 1880-1923. Paris : École Nationale Supérieure des Beaux-Arts.

SCOCCO, G. (2008). 'Un espacio permitido: educación artística y participación activa de la mujer en las artes decorativas y aplicadas'. En M. I. Saavedra, Buenos Aires: artes plásticas, artistas y espacio público (págs. 209-247). Buenos Aires: Vestales.

SOSA de NEWTON, L. (2007). Las argentinas y su historia. Buenos Aires: Feminaria.

TRIBUNA. (1898). Notas metropolitanas (10 de diciembre). Buenos Aires.

VERA PEÑALOZA, R. (1910). “Acción concurrente de la mujer en la 'instrucción del pueblo' Medidas que pueden ponerse aún en práctica”. En Primer Congreso Patriótico de Señoras en América del Sud (págs. 128-139). Buenos Aires: Imprenta europea de M. A. Rosas.

ZUBIAUR, J. B. (1900). La enseñanza práctica é industrial en la República Argentina. Buenos Aires: Félix Lajouane.

\section{NOTAS}

1. Temma Kaplan define la conciencia femenina como el reconocimiento de lo que una clase, cultura y período histórico particular esperan de las mujeres, creando un sentido de derechos y obligaciones que provee fuerza motriz para la acción, de un modo diferente alos postulados por la teoría marxista o feminista. La conciencia femenina se concentra en los derechos, cuestiones sociales y supervivencia. Quienes poseen conciencia femenina aceptan el sistema de géneros 
sobre el cual se organiza su sociedad, ya que -al reproducir la tarea asignada a las mujeres de preservar la vida-, la conciencia emerge de la división del trabajo por sexo. Su acción es relevante y puede tener consecuencias revolucionarias, al politizar las redes de la vida cotidiana (KAPLAN, 1982: 545). Tanto si sirven a las derechas o a las izquierdas, las acciones femeninas desestabilizan los estereotipos de docilidad y victimización femeninas (KAPLAN, 1982: 565).

2. Por otro lado, como ha demostrado Dora Barrancos, existieron fugas dentro del discurso patriarcal del Consejo Nacional de Mujeres, dando cuenta de la interacción entre diversos grupos de mujeres (BARRANCOS, 2008: 26-27).

3. La autora define de ese modo a los grupos femeninos con compromiso social no liberales, frecuentemente católicos y con fines más conservadores.

4. El CNM fue una asociación de diversos grupos que cubría gran parte del país. Fundado en 1900 a instancias de Cecilia Grierson, primera médica argentina, fue paulatinamente convirtiéndose en una sociedad filantrópica, al tiempo que entabló vínculos con grupos de extrema derecha. Sosa de Newton ha señalado que "no salió a la palestra de manera combativa para reclamar por los derechos femeninos sino que trabajó mucho en el aspecto cultural”. (2007: 144). La AUA tenía un perfil más renovador y la figura de Cecilia Grierson, ya distanciada del CNM, fue central. Ambas agrupaciones realizaron eventos para conmemorar el Centenario de la Revolución de Mayo de 1910. El Primer Congreso Patriótico de Señoras en América del Sud, organizado por el CNM, contó con el apoyo oficial de la Comisión del Centenario y recibió una amplia cobertura por parte de los diarios contemporáneos. Mientras el Congreso Patriótico se presentó como un homenaje a las llamadas patricias argentinas, el Congreso Femenino, realizado por la AUA, se planteó como objetivo explícito la discusión de la situación contemporánea de las mujeres y la reflexión acerca de los derechos cívicos. Dora Barrancos ha demostrado la existencia de vínculos entre estos grupos, relativizando las fronteras que los separarían (2002: 26-27). Además, ha resumido la complejidad de este modo: "el Consejo reunía a las mujeres más conservadoras, y en alguna medida ligadas a la Iglesia, no faltaban en sus filas las que exhibían sensibilidad social y preocupación por la condición de las trabajadoras" (2008: 12).

5. Por otro lado, esta iniciativa se sumaba a las opiniones de especialistas en el ámbito local. Zubiaur se refería al "carácter utilitario impuesto por el concepto actual de escuela y por la condición misma de los niños y jóvenes que... concurren” (ZUBIAUR, 1900: 269).

6. En el Primer Congreso Patriótico de Señoras en América del Sud Carolina Freyre de Jaimes señalaba: "El feminismo pide trabajo libre, el derecho del trabajo para aquellas á quienes no les toca en suerte el lote que lleva la barca de la vida por los mares risueños del amor y el matrimonio" (FREYRE DE JAIMES, 1910: 251).

7. Al respecto, Ehrenreich y English señalan que a fines del siglo XIX la ciencia se estaba convirtiendo en un valor. En todas las áreas, tornar algo en "científico" era sinónimo de reforma. Los sectores más progresistas reclamaron "administración pública científica", "crianza de niños científica", "trabajo social científico" y también "trabajo doméstico científico" (EHRENREICH Y ENGLISH, 1979: 69-70).

8. Abierta el 16 de octubre de 1898 en Buenos Aires, la Exposición Nacional, destinada a exhibir las múltiples riquezas del país, fue una iniciativa oficial. Se insertó en la serie de ferias y exposiciones que poblaron el siglo XIX y las primeras décadas del siguiente, con su habitual despliegue de productos y tecnologías. Es tristemente célebre por haber exhibido habitantes de Tierra del Fuego.

9. Al respecto debemos señalar que la participación argentina en dicho evento fue discutida en Buenos Aires, proponiéndose los nombres de Josefa Aguirre de Vassilicós y Amalia Solano para integrar la delegación nacional (EL NACIONAL, 1893: 5). Hasta donde sabemos, la Argentina no estuvo representada en la exposición.

10. Ahora bien, conviene no exagerar la valoración de las actividades manuales ejecutadas por mujeres de clases acomodadas. En rigor, diversas fuentes se refieren al escaso mérito atribuido a 
estas obras. Las páginas de La Columna del Hogar desplegaron este tema de modo explícito, destacando que eran muchos quienes creían que la aplicación a estas labores era "tiempo perdido" (LA COLUMNA DEL HOGAR, 1899: 1).

11. Entre las expositoras se hallaba, por ejemplo, María Güiraldes, esposa de José Prudencio de Guerrico, quien se dedicó a un 'coleccionismo de 'carácter menor' como abanicos, objetos japoneses, platería y cajitas francesas” (BALDASARRE, 2006: 152).

12. Su directora fue Catalina A. de Bourel. La Columna del Hogar comenzó como columna en el diario El Nacional en 1898. En líneas generales se trató de una publicación caracterizada por la profunda interacción entre mujeres conservadoras y progresistas, coexistiendo Gabriela Laperrière de Coni y Dolores Lavalle de Lavalle.

13. Al respecto, Laura Malosetti Costa ha señaladola marcada presencia femenina en las exposiciones del Ateneo. En el salón de 1894 las mujeres expositoras fueron veintisiete sobre sesenta y siete expositores (MALOSETTI COSTA, 2000)

14. Julia Wernicke (Buenos Aires, 1860 - 1932) estudió en Alemania y, a su regreso, intentó afianzarse como profesional, realizando exposiciones y participando de los salones del Ateneo. Su obra Toros, adquirida a instancias de Eduardo Schiaffino, integra la colección del Museo Nacional de Bellas Artes, siendo uno de los escasos trabajos de mujeres artistas nacidas antes de 1890 que figuran en ese espacio de legitimación.

15. El discurso de Quesada no pasó desapercibido y los sectores anti-feministas ridiculizaron sus palabras. Un diputado nacional, oculto bajo el pseudónimo de Benito Cristal, atacó duramente al orador. En primer lugar, el anónimo cronista señaló que el auditorio, aunque mayormente femenino, no se interesó por sus palabras. Las damas presentes estaban a salvo de "esas novedades por esa adorable feminidad que es el rasgo mas pertinente de su caracter y de su tranquila fisonomia moral". El feminismo era una empresa inútil: "no resiste al mas ligero exámen y... denuncia todo su juego cuando se llega á saber que las mas entusiastas, las mas apasionadas propagandistas son viejas, feas y solteronas!” (TRIBUNA, 1898: 2).

16. Las actividades incluían la pintura sobre diversos soportes, el bordado, el trabajo en cuero, la joyería, la confección de ropa, la realización de flores y el tejido.

17. En general, las escuelas de artes y oficios se concebían como la enseñanza ideal para "niños expósitos, huérfanos é hijos de padres pobres" (REGLAMENTO DE LA ESCUELA DE ARTES Y OFICIOS DE LA PROVINCIA DE BUENOS AIRES, 1896: 3).

18. José Benjamín Zubiaur contraponía la "escuela antigua, limitada, para la mujer, á enseñarle á leer, escribir y rezar" a la escuela moderna, encargada de dotar a las niñas de conocimientos otrora adquiridos en el hogar" (1900: 343). El educador defendía una educación basada en la "misión de ama de casa", que sustentaba todos los programas, siendo sus funciones eran "cuidar, consolar, estimular á sus maridos é hijos, dirigir la casa, de gastar y ahorrar y de hacer sus compras" (ZUBIAUR, 1900: 345).

19. Pese al silencio de la literatura artística y a los estereotipos de las mujeres artistas como aficionadas dedicadas a la pintura de flores, las artistas activas en Buenos Aires en el cambio de siglos abordaron diversos géneros con variados grados de éxito y visibilidad en el campo artístico.

20. Lola Mora (Tucumán, 1867- Buenos Aires, 1936) es una de las artistas más célebres de la historia del arte argentino. Comenzó su educación en el Colegio Sarmiento, donde recibió clases de dibujo. Tras la muerte de sus padres, ocurrida en 1885, comenzó sus estudios de pintura bajo la guía de Santiago Falcucci (1856-1922), maestro italiano llegado a Tucumán en 1887 y autor de uno de los primeros bosquejos biográficos de Mora. Entre 1897 y 1900 residió en Italia gracias a una beca gestionada por influyentes políticos. A su regreso, obtuvo importantes encargos oficiales y privados en Buenos Aires y Tucumán. Tras un acotado período de intensa actividad, entre 1900 y 1907, la carrera de Mora sufrió reveses inesperados, al tiempo que las élites políticas que la habían protegido comenzaban a perder poder. Sofía Posadas (Buenos Aires, 1859 - 1938) ha 
ingresado a la historiografía del arte de la mano de Laura Malosetti Costa, gracias a un escándalo protagonizado por Idilio, un desnudo exhibido en 1891 (MALOSETTI COSTA, 2000). Su obra abarcó también la pintura de historia, las escenas de género, el retrato, la naturaleza muerta y el paisaje. A fines del siglo XIX estudió en París, en una academia no identificada.

21. María Obligado (Buenos Aires, 1857 - Ramallo, 1938) fue una de las artistas más prolíficas del cambio de siglos. Habiendo estudiado en la Académie Julian, en París, desarrolló una vastísima obra que abarca la pintura de historia, el retrato, el paisaje y el género costumbrista. Expuso en el Salon de la Société des Artistes Français en cuatro oportunidades y en diversas muestras en Buenos Aires, entre ellas la realizada en conmemoración del Centenario de la Revolución de Mayo. Hortensia Berdier (Buenos Aires, 1862 - 1938) produjo una pequeña obra de altísima calidad, exhibiendo en diversas oportunidades, la última en 1912. Actuó, a partir de la década de 1920, en la Liga Patriótica.

22. Se podría pensar que Bonheur constituyó una versión femenina de Millet, cuya historia también se convirtió en motivo de obsesión para artistas y críticos de arte (MALOSETTI COSTA, 2005). Hemos abordado el tema en "Women and art in 19th century Buenos Aires: the French model and the case of Rosa Bonheur" (GLUZMAN, 2013b).

23. Mundial Magazine, por ejemplo, también hizo mención a esta noticia pero sin ninguna connotación explícitamente feminista sino más bien como una curiosidad.

24. Agradecemos al Lic. Diego A. Ruiz por esta referencia.

25. Al respecto, Grierson señalaba: "Me inclino á admitir que en nuestro país, deben favorecerse las industrias que permitan á la mujer permanecer el mayor tiempo posible en su hogar. Entre los trabajos que pueden realizar al mismo que vigila la casa y la familia, ó que pueda desempeñar en el domicilio de sus clientes, hallo muy indicados á sus aptitudes los siguientes : costurera, cortadora, confeccionadora de sastrería, chalequera, modista, zurcidora, bordadera, encajera, tejedora al bobillo, sombrerera, plumera, lavandera, planchadora, tintorera, peluquera, perfumista, florista de flores artificiales, florista de flores naturales, jardinera, horticultora, lechera, (quesería y mantequeria), criadera de aves, cabañera, relojera, cerrajera, tallista en madera y marmol, copista, calígrafa, dactilógrafa ; dibujante y cortadora de modelos y patrones de muebles, modas, etc. ; tapicera, estenógrafa, encuadernadora, escritora ; escultora en barro, mármol, ámbar, marfil, madera, etc. ; pintora en loza, porcelana, madera, telas, (seda, terciopelo), pergamino, marfil, abanicos, chicherías ; miniaturistas, acuarelista, fotógrafa, gerentes de hoteles, pensiones, etc., organizadoras de menús, banquetes y fiestas, empresaria de mudanzas ; directoras de asilo, hospitales é institutos ; enfermeras, parteras, masajistas [sic], dentistas, médicas, farmacéuticas, maestras de todo ramo, institutriz, etc." (1902: 193-194). Sin embargo, la propia Grierson manifestó serios reparos con respecto al desarrollo de los oficios artísticos: "Los bordados de toda especie, los encajes, pinturas, miniaturas, flores artificiales, plumas; modistas, y otros oficios ya enumerados tiene gran demanda por nuestras tendencias al lujo y ostentación" (1902: 200). Al mismo tiempo, deseó para ellos una enseñanza “industrial” (1902: 127).

26. La escuela instituida por la Sociedad Estímulo de Bellas Artes en 1878, nacionalizada en 1905, parece haber aceptado a mujeres desde fechas sumamente tempranas. A fines del siglo XIX, la presencia de las mujeres era masiva. Hasta donde sabemos, las estudiantes accedían a los mismos programas de estudio y recibían premios, aunque la coeducación aún no había sido introducida. Paralelamente, surgieron una plétora de academias -sostenidas por el gobierno municipal, dependientes de sociedades filantrópicas o privadas- que buscaron captar la creciente demanda de educación artística. Podemos mencionar, entre muchas otras, la Academia Perugino, la Academia Salvator Rosa y el Instituto Porrera, donde las bellas artes eran enseñadas junto a las artes aplicadas. A estas opciones, por supuesto, hay que sumar las clases privadas y grupales ofrecidas por artistas con mayor o menor reconocimiento, enfocadas a la enseñanza de dibujo y pintura. 


\title{
RESÚMENES
}

Las reflexiones en torno a la educación artística y a un grupo de mujeres artistas contemporáneas constituyen dos aspectos poco conocidos de las fructíferas relaciones entre artes y tempranos movimientos de mujeres. En primer lugar, el estudio de las escuelas para mujeres promovidas por estos movimientos así como el análisis de los múltiples discursos que las rodeaban ofrecen la oportunidad de explorar las fronteras entre el gran arte y las artes femeninas, destinadas a servir como medio de emancipación de las mujeres a través del trabajo remunerado. En este contexto, las coordenadas de género y clase social se imbrican decisivamente dando origen a discursos atravesados por la necesidad de elevar el gusto de las mujeres pertenecientes a clases medias y bajas. Por otro lado, ciertas artistas fueron saludadas como exponentes elocuentes del progreso femenino. Esta admiración encierra claves para comprender qué ideas en torno a la mujer artista fueron difundidas mediante publicaciones periódicas feministas y también cómo dialogaron con otros medios contemporáneos, también atentos a estas figuras.

Les réflexions sur l'éducation artistique et sur un groupe de femmes artistes contemporaines sont deux aspects peu connus de la relation fructueuse entre les arts et les mouvements des femmes. D'une part, l'examen des académies pour femmes promues par ces mouvements ainsi que l'analyse de multiples discours qui les entourent offrent l'opportunité d'explorer les frontières entre le prétendu grand art et les arts dits féminins, qui étaient destinés à rendre les femmes autonomes à travers un travail rémunéré. Dans ce contexte, les approches basées sur le genre et sur la classe sociale s'imbriquent et donnent lieu à des discours marqués par la nécessité d'élever le goût des femmes appartenant aux classes moyennes et basses. D'autre part, certaines artistes ont été saluées comme la démonstration du progrès féminin. Cette admiration détient les clés pour comprendre comment les idées sur les femmes artistes ont été diffusées par les périodiques féministes et comment ces femmes artistes dialoguaient également avec d'autres médias contemporains.

\section{ÍNDICE}

Mots-clés: art, mouvement des femmes, femmes artistes, éducation féminine, Argentine

Palabras claves: arte, movimiento de mujeres, mujeres artistas, educación femenina, Argentina

\author{
AUTOR \\ GEORGINA GLUZMAN \\ CONICET-UNSAM Doctoranda en Historia y Teoría de las Artes (Universidad de Buenos Aires) \\ georginagluz[at]gmail.com
}

